\title{
DEN KOSMOPOLITISKE HUMANISME OG RACISMEN CLAUDE LÉVI-STRAUSS SOM EKSEMPEL
}

\section{COSMOPOLITAN HUMANISM AND RACISM. CLAUDE LÉVI-STRAUSS}

AN EXAMPLE | In this article I discuss how cosmopolitan humanism, understood as the celebration and protection of cultural diversity which emerged in the field of the humanities, social sciences and politics after World War II, is related to modern racism. The point of departure of the discussion is an analysis of Claude Lévi-Strauss' descriptions of his travels in the former British India in the 1950's in his famous travelogue Tristes tropiques (1955). On the one hand Lévi-Strauss is considered a central figure in the fight against racism in the wake of World War II. He has written several widely influential texts in which he deconstructs old evolutionist myths and substitutes the notion of different races with the notion of different cultures. In addition, he has argued forcefully for the equality of all cultures and the benefits of intercultural exchange. But on the other hand he has also advocated cultural segregation. An example of this is his description of the Indian caste system not as a racist institution but as an ideal attempt to avoid racial conflicts by separating the different ethnic groups altogether. In my article I argue that this contradiction is not just due to an inconsistency in Lévi-Strauss' texts but rather the result of an inherent ambivalence in cosmopolitan humanism as such and in the cultural relativism on which it is based.

KEYWORDS | humanism, cosmopolitanism, anthropology, travel literature, cultural relativism, racism, Claude Lévi-Strauss, Tristes tropiques, "Race et culture"

I I97I holdt Claude Lévi-Strauss tale ved en UNESCO-konference i Paris. Her argumenterede han for, at moderne racisme ikke skal ses som et udslag af en ideologisk vildfarelse, men tværtimod som en naturlig reaktion på, at forskellige etniske grupper er blevet tvunget til at leve unaturligt tæt sammen i kølvandet på den tiltagende overbefolkning, migration og urbanisering. Han påstod samtidig, at etniske konflikter ikke kan løses gennem interkulturel dialog, åbenhed og tolerance, men kun ved at indføre en radikal segregationspolitik, der (gen)opretter grænserne de forskellige grupper imellem. Talen vakte stor forargelse blandt tilhørerne, fordi den var et angreb på den form for kosmopolitisk humanisme, som netop er associeret med UNESCO (Lévi-Strauss "Préface” I4ff). Den vakte samtidig også forundring, fordi Lévi-Strauss I9 år tidligere havde bidraget til UNESCO's bogserie om (og imod) racisme med essayet Race et histoire ("Race og historie"), som repræsenterer den selvsamme politiske linje, som han nu tilsyneladende vender sig imod. I Race 
et histoire (1952) dekonstruerer Lévi-Strauss det biologiske racebegreb og det deraf følgende kulturelle udviklingshierarki, som er grundlaget for den traditionelle evolutionistiske antropologi. Han hævder i stedet, at alle verdens samfund må forstås som sidestillede, lige udviklede kulturer med hver deres selvstændige, gensidigt usammenlignelige sæt af normer og værdier. Han opfordrer samtidig til dialog kulturerne imellem, idet "al kulturel progression er baseret på en koalition mellem kulturerne” (87). Baggrunden for, at Lévi-Strauss overhovedet blev inviteret til at tale ved UNESCO's konference var netop, at hans bog fra 1952 havde fået en enorm indflydelse på den måde, racismekritikken formede sig på efter 2. Verdenskrig. Det gjaldt både på et internationalt plan, hvor den bl.a. havde bidraget væsentligt til UNESCO's definering af sit kultursyn, og på et nationalt plan i Frankrig, hvor den havde opnået klassiker-status, var blevet genudgivet utallige gange og udgjorde en obligatorisk del af pensum i gymnasiet.

Hvor nogle af UNESCO's medlemmer efterfølgende udråbte Lévi-Strauss som en forræder og udstødte ham fra det gode selskab, forsøgte andre stiltiende at glemme hele episoden og fastholde billedet af ham som en af pionererne inden for bekæmpelsen af racismen (Lévi-Strauss "Préface" I4). Det interessante er imidlertid, at talen ikke blot eksponerer en indre modsigelse i Lévi-Strauss' eget politiske projekt, men også i UNESCO's - og i et bredere perspektiv i den kosmopolitiske humanisme som helhed. ${ }^{I}$ De tanker, Lévi-Strauss fremsætter i talen, står i virkeligheden ikke i modsætning til dem, han lancerede i 1952, men er tværtimod en direkte videreførelse af dem blot i en mere skarpt pointeret form (Christensen 83-84; Eriksen I36ff; Stjernfelt og Eriksen I75). Som Frederik Stjernfelt og JensMartin Eriksen har påpeget, er det, der adskiller Lévi-Strauss fra andre ligesindede intellektuelle, først og fremmest, at han driver den kosmopolitiske humanisme til dens yderste, at han på eksperimentel vis afprøver dens grænser, for på den måde med al tydelighed at udstille dens iboende modsigelse (I78). På den ene side hylder de kosmopolitiske humanister den kulturelle mangfoldighed og opfordrer til tolerance, åbenhed og interkulturel udveksling ud fra forestillingen om kulturernes grundlæggende ligeværdighed. Men på den anden side frygter de også, at en sådan udveksling, hvad enten den foregår på lige eller ulige præmisser parterne imellem, i længden vil nedbryde alle kulturelle forskelle og erstatte mangfoldigheden med en trist monokultur. De frygter samtidig, at udbredelsen af kendskabet til andre kulturer vil ødelægge det enkelte individs identitetsfølelse, dets tilhørsforhold til et specifikt kulturelt fællesskab, med en udbredt moralsk degeneration til følge. Selvom denne frygt kommer til udtryk i en stærkt radikaliseret form i talen fra I97I,

I Jeg bruger her den kosmopolitiske humanisme som en bred samlebetegnelse for det multifacetterede identitetspolitiske projekt om at dyrke og bevare verdens kulturelle mangfoldighed, der opstod efter 2. verdenskrig som en reaktion mod nazismen. Den kosmopolitiske humanisme tager afsæt i det tidlige 20. århundredes kulturrelativistiske antropologi og den dertil knyttede racismekritik, med amerikanske antropologer som Franz Boas, Ruth Benedict og Margaret Mead som nogle af de mest fremtrædende skikkelser. Foruden en indflydelsesrig international politisk organisation som UNESCO er nogle af den kosmopolitiske humanismes vigtigste aktører i efterkrigstiden uddannelsesinstitutioner, etnografiske museer og ikke-statslige organisationer. 
er den allerede latent tilstede i Race et histoire. Umiddelbart efter at Lévi-Strauss har fremsat sin berømte tese om "en koalition mellem kulturerne”, understreger han nemlig, at en sådan koalition er funderet på det uløselige paradoks, at den kun fungerer i kraft af kulturernes indbyrdes forskellighed, samtidig med at den med tiden bidrager til at homogenisere kulturerne (87).

En tekst som mere end nogen anden eksponerer denne implicitte modsigelse i den kosmopolitiske humanisme er Lévi-Strauss' Tristes tropiques fra I955. Tristes Tropiques er en yderst selvrefleksiv rejseberetning, som kombinerer retoriske strategier fra selvbiografi, etnografi, filosofi, litteratur og politisk kritik. Bogen er først og fremmest en skildring af Lévi-Strauss' oplevelser under opholdet i Brasilien i 1935-39, hvor han var ansat som gæsteprofessor i sociologi ved Universidade de São Paulo og samtidig deltog i flere etnografiske feltekspeditioner. Men den er samtidig også beretningen om en anden rejse, nemlig Lévi-Strauss' flugt til USA via Martinique i I94I, hvor han som jøde og venstreorienteret intellektuel måtte drage i eksil efter den tyske invasion af Frankrig. I bogens kapitel 2 beskriver Lévi-Strauss sine to rejser over Atlanten, der umiddelbart er så forskellige, som de overhovedet kan blive, (I6-24). Da han rejser til Brasilien i 1935 er det som en ung, håbefuld akademiker fuld af eventyrlyst og med en strålende karriere foran sig. Da han seks år senere rejser til USA, er det som en politisk flygtning, der i al hast må forlade sit hjemland pga. Vichy-regeringens jødeforfølgelse. Mens rejsen til Brasilien foregår på første klasse ombord på en damper med plads til Ioo-I50 personer, men hvor de kun er otte-ti passagerer, bliver Lévi-Strauss på rejsen til Martinique stuvet sammen med 350 andre mennesker på en damper med kun syv køjepladser. Han giver en malende beskrivelse af, hvordan den elementære mangel på mad, søvn, plads og ikke mindst sanitære forhold på skibet mod Martinique gør den ugelange overfart til én lang pinsel for ham og hans medpassagerer. Han beskriver desuden den kølige modtagelse, de får ved ankomsten til Martinique, hvor de lokale myndigheder snarere behandler dem som straffefanger end flygtninge.

Gennem modstillingen af de to rejser kontrasterer Lévi-Strauss også indirekte sit eget ideologiske ståsted med nazisternes. Han skaber en fortælling, hvor han på én gang optræder i rollen som helt og offer: Som én, der både kæmper imod den diskrimination, nazismen repræsenterer, og selv ender med at blive offer for den. Hvor Lévi-Strauss' etnografiske arbejde er motiveret af ønsket om at bevare andre kulturer ved at beskytte dem mod hans egen (europæiske) kulturs indflydelse, handler det for nazisterne omvendt om at bevare deres egen (germanske) kultur ved at beskytte den mod udefrakommende kulturel indflydelse. I begge tilfælde er der imidlertid tale om en særlig segregationspolitisk tænkning baseret på forestillingen om, at udveksling på tværs af kulturerne dræber menneskenes kreativitet og resulterer i identitetsløshed. Denne lighed kommer tydeligt til udtryk i beskrivelsen af en helt tredje rejseoplevelse i Tristes tropiques, nemlig Lévi-Strauss' forskningsophold i Indien og Pakistan i 1950, som ironisk nok netop var finansieret af UNESCO (Wilcken I80). 


\section{Indien som dystopi}

Mens Lévi-Strauss' skildring af sine videnskabelige ekspeditioner i Brasilien er en velkendt, hyppigt kommenteret del af Tristes tropiques, er hans beskrivelser af sine rejser i Indien og Pakistan generelt blevet ignoreret af receptionen. I den første engelske oversættelse af Tristes tropiques fra 196I, A World on the Wane af John Russell, er de fire kapitler, hvor Lévi-Strauss fortæller om sine oplevelser i Indien og Pakistan, endda direkte udeladt (kapitel I4-I6 og 39). Det er samtidig bemærkelsesværdigt, at mange engelsksprogede kritikere stadig benytter sig af Russells oversættelse, selvom der også eksisterer en senere engelsk version af bogen fra 1974, Tristes tropiques af John og Doreen Weightman, som er baseret på værket i dets fulde længde. Forklaringen på dette er ganske enkelt, at Lévi-Strauss i kapitlerne om Indien og Pakistan fremsætter en række kontroversielle påstande, som ikke umiddelbart stemmer overens med det officielle billede af ham som en af det 20. århundredes største humanister.

I Lévi-Strauss' optik er de sydamerikanske troper et billede på menneskehedens fælles fortid, et tabt paradis, som besynges i højtsvungne patetiske toner. Det skyldes både, at det er et af de mest øde, uberørte steder på jorden, og at det er et af de eneste steder i verden, hvor der endnu er nogle få uspolerede, såkaldt primitive stammefolk tilbage. Indien er med sin massive overbefolkning omvendt et dystopisk billede på menneskehedens nært forestående kollektive fremtid. ${ }^{2}$ Det er ifølge LéviStrauss indbegrebet af de mange dårligdomme, som globaliseringen har ført med sig: undertrykkelse, udbytning, fattigdom og forurening. Han understreger denne forskel mellem en moderne, globaliseret levevis og en traditionel, lokalt forankret levevis ved at sammenligne de indiske markeder med de sydamerikanske (kapitel I6). På de sydamerikanske markeder er sælgerne lokale bondekoner, der har medbragt en kurv med det sparsomme overskud fra den hjemlige husholdning som f.eks. en hjemmelavet lerkrukke, en gammel talisman, et par æg og nogle få bundter med blomster og grøntsager (I63). Lévi-Strauss kalder dette for "et produktionssystem, som er forblevet individualiseret” (I63), fordi den enkelte markedsbod afspejler sælgerens egenart. På de indiske markeder er varerne langt mere standardiserede, samtidig med at udbuddet er betydeligt større:

"Jeg har besøgt frugt- og grøntsagsmarkederne med deres bjerge af auberginer, lyserøde løg og skinnende granatæbler, som afgav en berusende duft af guava; blomstermarkeder, hvor blomsterhandlere flettede guirlander af roser og jasmin med glitter og englehår (...) Jeg har set stegekokkene, ostemassemagerne og pandekagebagerne - nãn eller chapati - te- og limonadesælgerne, engrosforhandlerne, hvis dadler hober sig op i klistrede dynger af frugtkød og kerner, som minder om en dinosaurus' ekskrementer; konditorerne, som kunne forveksles med fluesælgere,

2 Når Lévi-Strauss taler om Indien under ét, er det område, han refererer til, i virkeligheden Britisk Indien, som blev opløst med Storbritanniens tilbagetrækning og oprettelsen af staten Pakistan i 1947. 
der har linet deres varer op på en bund af kage; kobbersmedene, som kan høres på hundrede meters afstand pga. deres hammeres høje rumlen; kurvemagerne og rebslagerne med deres gule og grønne bast...” (I64-65).

Denne æstetiserede beskrivelse af markedernes babylonske forvirring af sanseindtryk vidner om en vis fascination fra Lévi-Strauss' side; en fascination, der dog samtidig er blandet med væmmelse. For trods deres tilsyneladende pittoreske charme er markedernes umage blanding af madvarer, isenkram og plastiktingeltangel fra hele verden i Lévi-Strauss optik et billede på globaliseringen i den mest negative version. Disse markeder vidner om et samfund, hvor distributionen af hjemmelavede, lokalt producerede varer baseret på ældgamle håndværksteknikker er blevet erstattet af en industriel masseproduktion baseret på international eksport.

Lévi-Strauss fortæller den tragiske historie om, hvordan den indiske landbefolkning, der blot for få generationer siden var selvstændige vævere, nu er blevet indlemmet $\mathrm{i}$ en verdensomspændende bomuldsindustri: nogle af dem som sælgere, der falbyder bomuldsstoffer fra Manchester på de lokale markeder; andre som syersker på tekstilfabrikkerne, der eksporterer til USA og Europa. Disse fabriksansatte lever og arbejder samtidig under nogle næsten koncentrationslejrlignende forhold, hvor manglen på frisk luft, lys, mad, hvile og sanitet er alarmerende. Den lomme-sociologiske analyse, som er flettet ind i beskrivelsen af disse forhold, har en stærk marxistisk undertone:

"Fra ende til anden lever de under et fremmedgjort system. Råmaterialet er fremmed, fuldstændigt fremmed for væverne i Demra, som bruger tråd importeret fra England eller Italien, og delvist fremmed for knappemagerne i Langalbund, hvor skallerne er af lokal oprindelse, men ikke kemikalierne, kartonet og folien, som også er nødvendig i deres industri. Og overalt er produktionen lagt an according to foreign standards. Disse stakler har næsten ikke selv råd til klæder på kroppen og endnu mindre til at have knapper i dem.” (I68).

I Lévi-Strauss' optik er fremmedgørelsen dog ikke kun som hos Marx et produkt af den kapitalistiske produktionsform, men også af de globale betingelser, som produktionen foregår på. Både råmaterialet, bearbejdningsprocessen og det færdige produkt er forankret $\mathrm{i}$ en anden kulturel kontekst end fabriksarbejderens egen, hvorved enhver form for identifikation forhindres. Produktionen er ikke alene så standardiseret, at det er umuligt for den enkelte arbejder at sætte sit individuelle præg på produktet; den er også iværksat efter en fremmed kulturs standard. Lévi-Strauss' eksempel har til formål at illustrere, hvordan klasseforskelle ikke kun manifesterer sig inden for det enkelte samfund, men også mellem samfundene, eller rettere mellem de tidligere kolonimagter og deres kolonier. Hans pointe er samtidig, at klassekampen blot er en slet skjult kulturkamp, hvor én kultur undertrykker andre kulturer. 
Forklaringen på, hvorfor den kulturelle diskrimination er så udbredt et problem netop i Indien, skal ifølge Lévi-Strauss findes i landets høje befolkningstæthed, der er et resultat af den massive urbanisering, som globaliseringen har affødt. Når et områdes befolkningstæthed stiger og dets forskellige kulturelle grupper af samme grund tvinges til at bo tættere på hinanden, blomstrer racismen op: "Når menneskene begynder at føle sig indeklemte i deres geografiske, sociale og mentale habitat, risikerer de at lade sig forføre af en simpel løsning, som består i at nægte en del af menneskeheden menneskeværd” (I70). Resultatet af racismens opblomstring er oprettelsen af et klassesamfund, hvor nogle kulturelle grupper underlægger sig andre.

Lévi-Strauss fremdrager Indiens kastesystem som et eksempel på, hvordan man netop har forsøgt at forhindre racismen ved at inddele befolkningen i nogle separate grupper, hvis fredelige sameksistens var betinget af deres gensidige uafhængighed. Projektet slog imidlertid fejl:

"Det er tragisk for menneskeheden, at dette storstilede eksperiment slog fejl, det vil sige, at det i historiens løb ikke er lykkedes kasterne at nå frem til en tilstand, hvor de kunne forblive ligestillede, fordi de er forskellige - lige i den forstand at de ville have været usammenlignelige - men at den forræderiske dosis af homogenitet vandt indpas blandt dem, som tillader sammenligning og dermed også oprettelsen af et hierarki. Menneskene kan leve sammen på den basis, at de anerkender alle som forskellige, men lige meget mennesker, men de kan også leve sammen ved at nægte hinanden en sammenlignelig grad af menneskeværd og dermed etablere et under- og overordningssystem." (I70).

Lévi-Strauss karakteriserer altså overraskende nok ikke kastesystemet som diskriminerende, men nærmere som et (om end mislykket) forsøg på at undgå diskrimination. Han mener samtidig, at europæerne bør tage ved lære af Indiens fejltagelser for ikke selv at gentage dem. Han perspektiverer landets sociale problemer til den politiske situation i Europa i I930'erne og 40’erne, som “i lyset af disse betragtninger (...) ikke længere skal forstås som følge af en vildfarelse fra et folks, en ideologis eller en gruppe menneskers side" (I70) men som en naturlig konsekvens af den fordobling af befolkningstallet, der fandt sted i samme periode. Det er altså ikke selve nazismen, der er det egentlige problem. Det er snarere den overbefolkning og det deraf følgende sammenstød mellem forskellige kulturer, som nazismen var en reaktion på.

\section{En racisme uden race}

Når Lévi-Strauss skildrer menneskeheden som opdelt i nogle sidestillede, separate kulturelle enheder, beskriver han ikke kun en de facto tilstand - verden sådan som den ifølge hans egen opfattelse er. Han fremsætter også et ideal, der foreskriver, hvordan verden burde være. Enhver form for kulturel blanding er således et brud 
på en naturlig verdensorden, en substitution af den oprindelige tilstand af harmoni med det, som han med et begreb hentet fra termodynamikken kalder for entropi. Kulturel blanding fører til interkulturel sammenligning, der igen uundgåeligt fører til oprettelsen af et kulturelt hierarki. Hans forslag til, hvordan man kommer racismen til livs, er derfor heller ikke at nedbryde grænserne mellem de stridende parter i etniske konflikter gennem dialog, men snarere at adskille parterne helt ved at konsolidere grænserne, gøre dem absolutte. Og det kan kun lade sig gøre ved at skabe en større fysisk afstand de enkelte grupper imellem. Lévi-Strauss' forbillede er som tidligere nævnt de sydamerikanske troper, hvor små stammefolk ifølge hans opfattelse i årtusinder har levet fredeligt side om side netop pga. deres geografiske adskillelse.

Etienne Balibar argumenterer i artiklen "Y a-t-il un 'néo-racisme?" ("Findes der en 'neoracisme'?") fra I988 for, at dele af den intellektuelle elite i Frankrig, der tilslutter sig den kosmopolitiske humanisme, er med til at skabe det teoretiske fundament for en racistisk praksis. Hans eneste konkrete eksempel, der dog blot nævnes en passant, er netop Lévi-Strauss, som "hvad enten det er frivilligt eller ej, må se sig indfanget af ideen om, at 'blandingen af kulturer' og undertrykkelsen af 'kulturelle afstande' er ensbetydende med menneskehedens intellektuelle død” (34). Balibar betegner denne type racisme "en meta-racisme, eller det vi kan kalde for en 'andenpositionsracisme' (un racisme de 'seconde position')” (35). Den moderne meta-racisme adskiller sig ifølge Balibar primært fra den traditionelle racisme på to punkter: For det første er der tale om en "racisme uden race" (36), hvor det pseudovidenskabelige racebegreb er blevet erstattet af kulturbegrebet. Denne forskydning medfører dog ingen opblødning af den traditionelle racismes rigide determinisme, idet kultur opfattes som et lige så naturgivent vilkår som race:

"Det som ses her er, at biologisk eller genetisk naturalisme ikke er den eneste måde at naturalisere menneskelig adfærd eller socialt tilhørsforhold på. På bekostning af opgivelsen af den hierarkiske model (selvom denne opgivelse er mere tilsyneladende end reel, som vi skal se), kan kulturen også komme til at fungere som en slags natur, ikke mindst som en måde hvorpå individer og grupper apriorisk kan fastlåses i en genealogi, i en determination, hvis oprindelse er uforanderlig og uhåndgribelig." (34).

For det andet skal meta-racismen i forlængelse heraf forstås som "en teori om 'etniske relationer' (eller racerelationer) i samfundet, som ikke naturaliserer racemassige tilhørsforbold men racistisk adferd" (35). Karakteristisk for meta-racismen er netop, at den i forsøget på at udrydde racismen i virkeligheden legitimerer den. Selvom meta-racisterne er erklærede humanister, der anser alle mennesker uanset kulturelt tilhørsforhold for at være lige, er denne lighed i deres forståelse betinget af en absolut adskillelse kulturerne imellem. For at undgå racismen må man derfor ifølge meta-racismen undgå den humanistiske anti-racisme, som opfordrer til tolerance, og i stedet - i lighed med racisterne - insistere på kulturel segregation. Meta-racismen fremstiller netop sig selv som "den sande antiracisme og derfor den sande humanisme" (36). 
Problemet med meta-racismen er dog ikke kun, at den er en retrospektiv teoretisk legitimering af en allerede eksisterende racebaseret racisme. Det er også, at den har en performativ funktion, dvs. at dens teorier omsættes direkte til en racistisk identitetspolitisk praksis. Hvis man skulle udvide Balibars argumentation en smule, kunne man endda sige, at tilføjelsen "meta” i dag er blevet overflødig, fordi den racistiske racisme er veget for det, man med Stjernfelt og Eriksens betegnelse kunne kalde en kulturalistisk racisme - eller blot kulturalismen (I29ff). 3 Racismen har, som Balibar også selv pointerer, altid manifesteret sig i vekselvirkningen mellem teori og praksis (I8-I9). Men hvis det i det I9. århundrede var den evolutionistiske antropologi, der udgjorde racismens teoretiske grundlag, er det i det 2O. og 2I. århundrede i høj grad den kulturrelativistiske antropologi, der har overtaget denne rolle. Det er dog ikke ensbetydende med, at man uden videre kan sætte lighedstegn mellem den kulturrelativistiske antropologi og den kulturalistiske variant af racismen. Hvis der omkring forrige århundredeskifte var en direkte, gensidigt legitimerende relation mellem den evolutionistiske antropologi og den racebaserede racisme, er relationen mellem den kulturrelativistiske antropologi og den moderne kulturalistiske racisme langt mere ambivalent. Denne ambivalens kan lokaliseres på to niveauer: Dels i skismaet mellem en rent deskriptiv, videnskabelig repræsentationsform og en normativ, politisk praksis og dels inden for selve den normative, politiske praksis i skismaet mellem en kosmopolitisk humanisme og en kulturalistisk racisme.

\section{Kulturvidenskab og kulturkritik}

Som en videnskabelig disciplin, der har naturvidenskabens empirisme som forbillede, påberåber den moderne kulturrelativistiske antropologi sig en objektiv og i sig selv apolitisk repræsentationsform.4 Ikke desto mindre har den lige siden sin spæde begyndelse været politisk motiveret. Selv den moderne videnskabelige antropologis fader, Bronislaw Malinowski, der mere end nogen anden insisterer på et positivistisk videnskabsideal, proklamerede i I922, at "videnskaben om mennesket i dens mest raffinerede og dybdegående form bør lede os til en sådan viden og til tolerance og generøsitet, baseret på forståelsen af andre menneskers synspunkt” (5I8), hvilket er særligt vigtigt i en tid "hvor fordomme, ond vilje og hævngerrighed splitter de europæiske nationer” (5I8). På den ene side producerer den kulturrelativistiske antropologi en række etnografiske beskrivelser, der tilstræber en rent deskriptiv, værdineutral fremstillingsform. Men på den anden side er disse beskrivelsers implicitte formål en kritisk relativering af antropologernes egen (europæiske) kultur. Kulturrelativismens opdeling af verden i en række sidestillede, selvstændige og gensidigt usammenlignelige kulturelle enheder har paradoksalt nok altid været

3 Den moderne form for racisme, hvor race er blevet erstattet med kultur, går under flere forskellige betegnelser inden for moderne racismeteori, bl.a. farveblind racisme (Bonilla-Silva; Carr), differentierende racisme (Taguieff) og kulturel racisme (Seidel).

4 Dette gælder dog primært inden for den franske og britiske tradition, mens de amerikanske antropologer altid har spillet en mere aktiv rolle i den politiske debat. 
tæt forbundet med en komparativ kulturkritik. Og det primære formål med denne kritik er og bliver at forandre ens eget samfund.

I et af Tristes tropiques' sidste kapitler (kapitel 38) adresserer Lévi-Strauss eksplicit det problem, at kulturvidenskab og -kritik begge er en integreret, uundværlig del af antropologien, samtidig med at de gensidigt underminerer hinanden. Kapitlet er udformet som en art sokratisk dialog, som Lévi-Strauss fører med sig selv, hvor han først fremsætter et dilemma, dernæst et løsningsforslag, dernæst et nyt dilemma affødt af løsningsforslaget osv. Det første dilemma, som han påpeger, er, at etnograferne forholder sig kritisk til deres eget samfund og aktivt forsøger at forandre dette, mens de er fuldstændigt ukritiske over for de fremmede samfund, de studerer, og nostalgisk begræder enhver forandring af disse (458-59). Efter at have diskuteret (og forkastet) forskellige forslag til løsninger på dette dilemma, fremsætter han endnu et dilemma, som sætter ambivalensen mellem at være kritisk, revolutionær hjemme og ukritisk, reaktionær ude yderligere i perspektiv: Mange af de forhold, som etnografen kender fra sin egen kultur, f.eks. undertrykkelse, forekommer også i andre kulturer (462). Hvis etnografen vælger at kritisere disse forhold hjemme, må han for at være konsekvent også kritisere dem ude. Og omvendt: hvis etnografen forholder sig neutralt til disse forhold ude, må han gøre det samme hjemme (462). Problemet er i denne sammenhæng, at kulturerne i realiteten ikke er så forskellige, som kulturrelativismen forudsætter, hvilket vanskeliggør fastholdelsen af en ikke-komparativ tilgang. I det øjeblik andre kulturer fratages deres absolutte fremmedhed, fratages etnografen nemlig også sin absolut udefrabeskuende, desinteresserede position i forhold til disse og bliver i stedet en engageret deltager i det kulturelle spil.5

Lévi-Strauss forsøger efterfølgende at overvinde modsigelsen mellem at være revolutionær hjemme og reaktionær ude ved at skelne mellem to forskellige former for kulturkritik, som samtidig repræsenterer to forskellige faser i etnografens arbejde: Først må etnografen vende sig mod sin egen kultur gennem studiet af andre kulturer. Han må m.a.o. tage afstand fra de hjemlige normer, alene fordi de er hjemlige (470). Formålet med dette er imidlertid ikke at konvertere til en anden kultur, at bevæge sig fra én kulturelt indskrænket position til en anden, men snarere at frigøre sig fra ethvert kulturelt situeret perspektiv gennem erkendelsen af alle kulturers relativitet. ${ }^{6}$ Herefter er etnografen rustet til at anlægge et kulturkritisk perspektiv af mere videnskabeligt tilsnit; en kritik, der ikke retter sig

5 Med fremsættelsen af dette dilemma foregriber Lévi-Strauss to af de væsentligste kritikker, som de seneste tre-fire årtier er blevet rettet mod den kulturrelativistiske antropologi: Dels kritikken af forestillingen om kulturerne som adskilte, autonome enheder og dels kritikken af forestillingen om antropologen som en neutral, udefra beskuende og desinteresseret figur og antropologien som en objektiv videnskab. Et af de tidligste og mest programmatiske eksempler på en sådan kritik finder vi hos den amerikanske antropolog James Clifford, der var en af de ledende skikkelser inden for den såkaldte retoriske vending i antropologien i 1980'erne. Se bl.a. Clifford og Marcus Writing Culture, Clifford The Predicament of Culture og Clifford Routes.

6 Evnen til at anlægge et tilstrækkeligt fordomsfrit blik på andre kulturer er dog, hvis vi skal følge Lévi-Strauss' egen logik, i sig selv betinget af en forudgående kritisk distance til ens egen. Det forbliver således uklart, om kulturvidenskaben forudsætter kulturkritikken eller omvendt. 
mod de enkelte kulturers indre relationer, deres partikulære normer, værdier eller vaner, men snarere mod deres ydre relationer, mod den måde de forholder sig til hinanden på. Og i denne sammenhæng rettes kritikken endnu engang primært mod europæerne, fordi de i modsætning til de fleste andre folkeslag ikke blot ringeagter andre folkeslags kulturer, men også har gjort et storstilet forsøg på at udrydde disse til fordel for udbredelsen af deres egne normer, vaner og værdier (466). Problemet med europæerne er m.a.o., at de i kraft af deres imperiale projekt nedbryder den naturlige adskillelse kulturerne imellem og installerer dem i en hegemonisk relation.

Denne imperialismekritik eksponerer et centralt paradoks i kulturrelativismen, som samtidig er selve kernen i dens skisma mellem kulturvidenskab og kulturkritik: Hvis kulturrelativisterne anerkender de kulturer, der forbryder sig mod kulturrelativismens princip om kulturernes ligeværdighed, på lige fod med andre kulturer, bidrager de så at sige til en indefrakommende underminering af deres eget ideologiske grundlag. Hvis de omvendt (som Lévi-Strauss vælger at gøre) nægter at anerkende disse kulturer på lige fod med andre, gør de sig til gengæld skyldige i den selv samme hierarkisering, som de beskylder disse kulturer for at foretage.

\section{Kosmopolitisk humanisme og kulturalistisk racisme}

Lévi-Strauss' kulturkritik omsættes i et særdeles modsigelsesfyldt politisk projekt, der adresserer spørgsmålet om, hvordan en given stat skal administrere relationen mellem divergerende etniske grupperinger inden for dens egne grænser. Dette politiske projekt udspiller sig som demonstreret i analysen af Indiens-beskrivelserne i Tristes tropiques mellem en kosmopolitisk humanisme og en kulturalistisk racisme. En tekst, der belyser denne ambivalens fra en lidt anden side, er Lévi-Strauss' tidligere nævnte tale ved UNESCO i I97I, som senere blev publiceret under titlen "Race et culture" ("Race og kultur") i essaysamlingen Le Regard Eloigné (1983) og dermed nåede ud til et bredere publikum.7 Her argumenterer Lévi-Strauss bl.a. for, at man kan skelne mellem en sund og en usund form for fremmedfjendskhed, hvoraf kun den sidstnævnte kan kaldes racisme:

"Så længe kulturerne anerkender deres indbyrdes mangfoldighed, kan de enten frivilligt ignorere hinanden eller anse hinanden for at være partnere i en gensidigt ønsket dialog. I begge tilfælde vil de af og til true og angribe hinanden, men uden for alvor at bringe hinandens respektive eksistens i fare. Situationen er helt anderledes, når begrebet om gensidigt anerkendt diversitet erstattes af én kulturs overlegenhedsfølelse baseret på magt, og når den positive eller negative anerkendelse af kulturernes diversitet erstattes af bekræftelsen af deres uligeværdighed.” (26-27).

Det er imidlertid kun den sunde, "naturlige" form for fremmedfjendskhed, der er et produkt af manglende viden om andre kulturer. Den usunde form, racismen,

7 For en mere udfoldet kritik af den indbyggede racisme i "Race et culture", se Taguieff: 6o-6I, I54-56. 
skyldes omvendt, at de enkelte kulturer pga. overbefolkning er tvunget til at leve så tæt sammen, at der uvægerligt opstår konflikter mellem dem:

"Men er vi så sikre på, at den racistiske form for intolerance først og fremmest er et resultat af den ene eller den anden befolkningsgruppes falske forestilling om den kulturelle evolutions afhængighed af den biologiske evolution? Er disse forestillinger ikke blot et ideologisk dække for nogle mere reelle modsætninger baseret på begæret efter at underkue andre befolkningsgrupper og fastholde en magtposition? Sådan var det afgjort førhen. Men selv hvis disse magtrelationer nu er ved at formindskes, er forestillingen om raceforskelle så ikke stadig et symptom på de tiltagende vanskeligheder med at leve sammen, som menneskeheden ubevidst føler i kølvandet på befolkningseksplosionen?” (43).

Lévi-Strauss mener derfor, at den kosmopolitiske humanisme, som UNESCO repræsenterer, har spillet fallit i kampen mod racisme. Racismen kan ikke bekæmpes gennem interkulturel dialog, forståelse og tolerance, men kun gennem en segregationspolitik, der opretholder grænserne kulturer imellem.

Dette er for så vidt en gentagelse af de pointer, som allerede blev fremført i Indiens-beskrivelserne i Tristes tropiques. Men i "Race et culture" fremfører LéviStrauss også en anden kritik af den kosmopolitiske humanisme, nemlig at den har bidraget til nedbrydelsen af den sunde, "naturlige" form for fremmedfjendskhed og dermed til ophævelsen af de absolutte grænser kulturerne imellem, som i LéviStrauss' optik er forudsætningen for diversiteten:

"Man kan dog ikke lægge skjul på, at kampen mod alle former for diskrimination, på trods af dens påtrængende praktiske nødvendighed og høje moralske mål, er del af den samme bevægelse, som fører menneskeheden mod én verdenscivilisation, og som ødelægger de gamle partikularismer, der har æren for at have skabt de æstetiske og åndelige værdier, som giver livet værdi, og som vi omhyggeligt indsamler på biblioteker og museer, fordi vi føler os stadigt mindre i stand til selv at producere dem.” (47).

Problemet med den kosmopolitiske humanisme er i denne forståelse ikke, at dens projekt om mellemfolkeligt samvirke er mislykkedes, fordi det blot har styrket fremmedfjendskheden. Det er tværtimod, at projektet er lykkedes alt for godt, dvs. at de kosmopolitiske humanister efterhånden er blevet så talrige, at der er desto færre "ægte" kulturmedlemmer tilbage - dvs. dem som er så integrerede i deres egen kultur, at de betragter dens partikulære normer og værdier som universelle. Og det er paradoksalt nok netop dem, som de kosmopolitiske humanister baserer deres teori om kulturernes autonomi på. På den ene side er Lévi-Strauss mere end nogen anden repræsentant for den kosmopolitiske humanisme. Som etnograf er han i sin egen selvforståelse netop en person, der er i stand til at bevæge sig ind og ud af forskellige kulturer uden at være personligt engageret i nogen af dem. Men 
på den anden side advarer han samtidig også eksplicit mod den kosmopolitiske humanismes udbredelse, idet han mener, at dens relativistiske, metakulturelle perspektiv bidrager til at nedbryde de selv samme grænser kulturerne imellem, som den er en hyldest til. Faren ved kosmopolitisk humanisme er, at den fratager mennesket dets kultur og dermed gør det identitetsløst:

"Men hvis menneskeheden ikke skal forfalde til at blive sterile konsumenter af de værdier, vi har skabt i fortiden, til kun at være i stand til at skabe bastardværker, grove og infantile opfindelser, så må vi lære igen, at al sand skabelse forudsætter en vis døvhed over for andre værdiers appel, endda gå så langt som til at afvise disse værdier eller ligefrem fornægte dem fuldstændigt. For man kan ikke nyde den Anden fuldt ud, identificere sig med ham, og samtidig forblive anderledes." (47). ${ }^{8}$

Lévi-Strauss forsøger at løse det skitserede dilemma ved at indtage en pragmatisk midterposition. Han anerkender på den ene side, at udveksling på tværs af kulturer er forudsætningen for deres respektive videreudvikling og dermed levedygtighed. Men samtidig fastholder han på den anden side, at en sådan udveksling kun bør finde sted i moderate mængder, fordi den potentielt kan resultere i nedbrydningen af alle kulturforskelle og dermed også enhver fremtidig udveksling. Udvekslingen har m.a.o. en iboende selvdestruktiv tendens, som skal holdes i ave, hvis den kulturelle kreativitet skal bevares. Hvordan dette rent praktisk skal realiseres, giver Lévi-Strauss ingen konkrete bud på i "Race et culture". Men tankerne ledes uvægerligt hen på politiske modeller som Apartheid, når han eksempelvis påstår, at "gensidig tolerance forudsætter to betingelser, som nutidens samfund er længere end nogensinde fra at opfylde: relativ ligeværdighed og tilstrækkelig fysisk afstand fra hinanden” (44).

Forklaringen på den kosmopolitiske humanismes indre modsigelser skal findes i den kulturrelativistiske tænkning, der er dens teoretiske grundlag. På den ene side er kulturrelativismen funderet på en grundlæggende antagelse om, at ethvert synspunkt er forankret i en specifik, partikulær kultur og dermed kun har relativ gyldighed. Men på den anden side undtager kulturrelativisterne samtidig deres eget relativistiske synspunkt fra denne generelle antagelse. De forudsætter således, med Søren Christensens formulering, at "indsigten i altings relativitet hæver erkendelsen over enhver relativitet" (4I). Resultatet er, at kulturrelativisterne indstifter en modsætning mellem de enkelte kulturmedlemmers snæversynede, determinerede perspektiv og deres egen frie, kosmopolitiske metaperspektiv (Christensen 40). Det er netop dette immanente paradoks, der gør, at kulturrelativismen i lige så

8 Dette forbehold over for ubegrænset kulturudveksling er ikke særligt for Lévi-Strauss, men har tværtimod været en integreret del af den kulturrelativistiske tænkning siden dens opståen i slutningen af I7oo-tallet. Kulturrelativismens fader, Johann Gottfried Herder, udtrykker det i 1774 således: "Men fordommen er god, i rette tid, thi den bringer lykke. Den trænger folkeslagene sammen til deres eget midtpunkt, fæstner dem stærkere til deres stamme, gør dem mere blomstrende på deres måde, mere lidenskabelige og lyksalige i deres tilbøjeligheder og formål” (58-59). 
høj grad kan bruges til at retfærdiggøre kulturel segregation som til at promovere interkulturel dialog og tolerance. Den bekræfter på én gang kulturernes "naturlige" forskellighed og det enkelte individs "naturlige" aversion mod alt, hvad der er forskelligt fra dets egen kultur. Selvom den kosmopolitiske humanisme i sin egen selvforståelse er racismens diametrale modsætning, er den altså i realiteten nært forbundet med denne. Racismens forekomst bekræfter den kosmopolitiske humanismes tese om den enkelte kulturs uundgåelige mistro over for andre kulturer, samtidig med at racismen i kraft af sin aktive indsats for at ekskludere det fremmede også bidrager til at opretholde den forskellighed, som den kosmopolitiske humanist dyrker. Som både Tristes tropiques og "Race et culture" med al tydelighed viser, opererer den kosmopolitiske humanisme i lige så høj grad som den kulturalistiske racisme (f.eks. nationalismen) med en segregationspolitisk tænkning baseret på en idealiseret forestilling om kulturen som en homogen, hermetisk lukket størrelse. Forskellen er blot, at den "oprindelige" kultur, som de kosmopolitiske humanister ønsker at bevare og beskytte mod udefrakommende indflydelse ikke som i den racistiske variant af kulturrelativismen er deres egen, men andres. Hvor segregationstænkningen i racismens tilfælde er baseret på xenofobi, er den i den kosmopolitiske humanismes tilfælde omvendt baseret på xenofili.

Det særlige ved Tristes tropiques er imidlertid, at den i langt højere grad end LéviStrauss' rendyrkede kulturteoretiske og -politiske tekster (som f.eks. "Race et culture") holdes åben for en grundlæggende tvivl i forhold til den kulturrelativistiske tænkning, som den er baseret på. Noget af det, der gør bogen interessant at arbejde med i dag, er, at Lévi-Strauss undervejs i sit storstilede forsøg på at sammentænke konventionelt adskilte genrer, teorier, videnskaber, kulturer, ord og begreber, støder ind i en række modsigelser, både inden for og mellem de enkelte genrer, teorier osv. I stedet for at tildække disse modsigelser, som truer med at underminere den enhedslige orden, han søger at etablere, vælger Lévi-Strauss imidlertid at konfrontere dem. Et eksempel på dette er netop den sokratiske dialog, som han fører med sig selv om relationen mellem kulturvidenskab og kulturkritik. Her forsøger han ikke at inddæmme modsigelserne inden for og mellem de to diskurser, men tager dem tværtimod eksplicit op til diskussion en efter en, hvorefter han åbent reflekterer over, om - og i så fald bvordan - de kan overvindes. Selvom intentionen med denne diskussion i sidste ende netop er at overvinde modsigelserne og dermed definitivt forene kulturvidenskab og kulturkritik, får diskussionen som eksemplificeret imidlertid snarere modsigelserne til at proliferere yderligere. Den stiller samtidig ikke kun spørgsmålstegn ved syntetiseringen af de to diskurser, men også ved deres gyldighed hver for sig betragtet. Tristes tropiques kan således læses som en performativ undersøgelse af, hvad der sker, hvis man drager den fulde konsekvens af den kulturrelativistiske tænkning. Den kan læses en afsøgning af den kulturrelativistiske tænknings grænser og af, hvor langt dens begrebsapparat kan strækkes, inden det bryder sammen. Hvis Tristes tropiques på den ene side er indbegrebet af den moderne kulturrelativisme, foregriber den på den anden side også det opgør med kulturrelativismen, som først slog igennem inden for kulturvidenskaberne tre-fire årtier efter dens udgivelse. 


\section{LITTERATURLISTE}

Balibar, Etienne. "Y a-t-il un 'néo-racisme'?" Race, nation, classe. Les identités ambiguës. Red. Etienne Balibar og Immanuel Wallerstein. Paris: Éditions La Découverte, 1988. 27-4I.

Bonilla-Silva, Eduardo. Racism Without Racists: Color-Blind Racism and the Persistence of Racial Inequality in America. Lanham, Maryland: Rowman and Littlefield Publishers, 2003.

Carr, Leslie G. 'Color-blind' Racism. Thousand Oaks, Californien: Sage Publications, 1997.

Christensen, Søren. Fakticitetens Ironi: Facetter af kulturrelativismens idéhistorie. Aarhus: Aarhus Universitetsforlag, I994.

Clifford, James. The Predicament of Culture: Twentieth-Century Ethnography, Literature, and Art. Cambridge, Massachusetts: Harvard University Press, 1988.

Clifford, James. Routes: Travel and Translation in the Late Twentieth Century. Cambridge, Massachusetts: Harvard University Press, 1997.

Clifford, James og George E. Marcus (red.). Writing Culture: The Poetics and Politics of Ethnography. Berkeley og Los Angeles: University of California Press, I986.

Eriksen, Thomas Hylland. "Between universalism and relativism: a critique of the UNESCO concept of culture”. Culture and Rights: Anthropological Perspectives. Red. Jane K. Cowan, Marie-Bénédicte Dembour og Richard A. Wilson. Cambridge: Cambridge University Press, 200I. I27-I48.

Herder, Johann Gottfried. Endnu en historiefilosofi til menneskehedens dannelse. Overs. fra tysk ved Adam Paulsen. Frederiksberg: Det lille Forlag, 2002.

Lévi-Strauss, Claude. "Préface”. Le regard éloigné. Paris: Plon, I983. II-I7.

Lévi-Strauss, Claude. "Race et culture". Le regard éloigné. Paris: Plon, I983. 2I-48.

Lévi-Strauss, Claude. Race et histoire. Paris: Denoël, 1987.

Lévi-Strauss, Claude. Tristes tropiques. Paris: Plon, 2010.

Malinowski, Bronislaw. Argonauts of the Western Pacific: An Account of Native Enterprise and Adventure in the Archipelagos of Melanesian New Guinea. London: George Routledge \& Sons, 1922.

Seidel, Gill. "Culture, Nation and 'Race' in the British and French New Right". The Ideology of the New Right. Red. Ruth Levitas. Cambridge, England: Polity Press, 1986. I07-35.

Stjernfelt, Frederik og Jens-Martin Eriksen. Adskillelsens Politik: Multikulturalisme - ideologi og virkelighed. København: Lindhardt og Ringhof, 2008.

Taguieff, Pierre-André. The Force of Prejudice: On Racism and Its Doubles. Minneapolis: University of Minnesota Press. 200I.

Wilcken, Patrick. Claude Lévi-Strauss: The Poet in the Laboratory. London: Bloomsbury Publishing, 20 Io. 